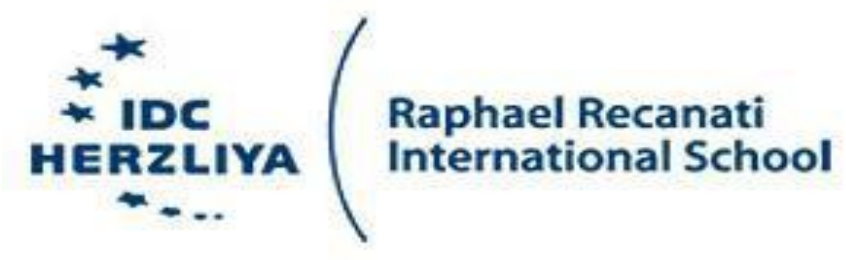

Seminar Paper

Advanced Topics in Social Network Analysis

\title{
How viral marketing can be implemented within Instagram advertising for small business?
}

Submitted by:

Oksana Storozhenko 


\section{Table of Contents}

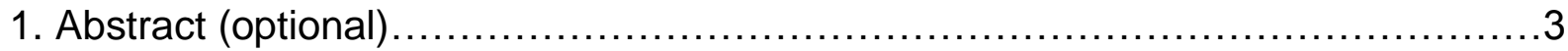

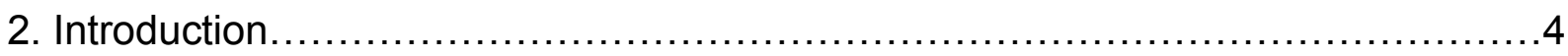

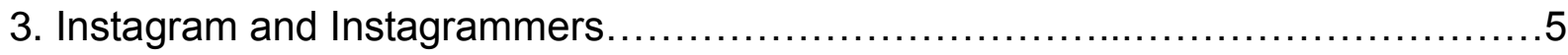

$3.1 \mathrm{eWOM}$ and Viral Marketing..........................................................

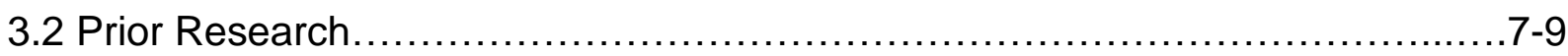

4. How viral marketing can be implemented within Instagram advertising for small

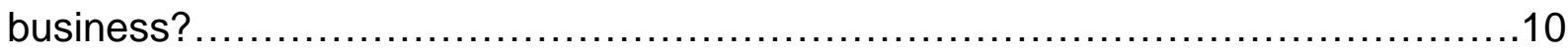

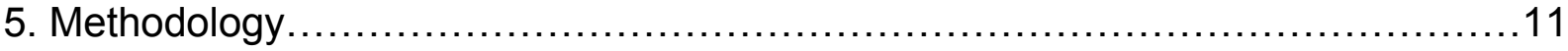

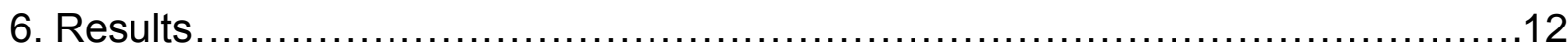

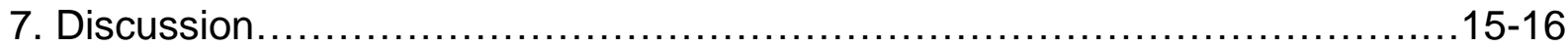

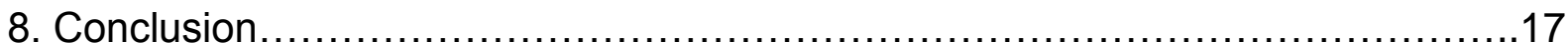

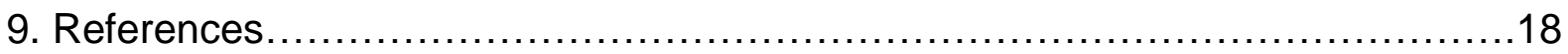

10. Appendices..................................................................... 


\section{Abstract}

As the Internet evolves and online social networks gain more trust in becoming our everyday shopping tool. Our perception of products and shopping experience changes within relying on bloggers in social networks, mostly common this phenomenon can be met at Instagram platform.

Through Buzilla tool and use of Instagram comments relationship between popularity of Farah Dhukai blogger and promotion of her beauty brand was investigated. Results suggested that there is no clear connection between hashtags and rise of her followers. Whereas, in the content of other bloggers were used eWom that was caused by crowdsourcing technique and successfully raised followers rate for Farah Dhukai and interest to her brand "Farsali". 


\section{Introduction}

Marketing activities depends on the society's development and will therefore always be in constant change. This paper was inspired by dramatic growth of popularity in shopping via Instagram, which already has its marketing value.

While observing own friends and family sharing their experiences of purchasing a product because of recommendation of some Instagrammer or blogger, created an idea of analyzing and establishing traits that support that process.

In the third section of this paper will be discussed concept of Instagram and its users implementation. Also will be discussed main theory on which based the entire work in order to implement research question and test hypothetical thoughts. At the end of section also elaborated on previous research that helped with shaping final research question.

In the fourth section will be presented research question and other hypothetical thoughts, while opening up philosophical discussion on topic and introducing sources of content examined further.

Where, in fifth section will be explained methodology and use of Buzilla tool for completing research. And more information about chosen method of analysis and sampled audience.

Section six and seven attributed to clear presentation of research's results and followed by discussion on how they influenced or related to main research question. And to sum all paper and draw the line section eight will present brief conclusion, that can be interpreted as final thoughts on completed research. 


\section{Istagram and Instagrammers}

Instagram is a community of more than 600 million who capture and share the world's moments on the service since 2010 (Instagram, 2017). With more than 400 millions daily actives, 700 millions monthly actives and 250 millions daily actives it continues to develop features (Instagram, 2017). While social interaction is a primary motivation of using Instagram, another important motivation is self-expression (Kim, 2017). Popularity here is not merely referring to the popularity of Instagram, instead referring to the fact that there's a lot of Instagrammers who are very, very popular on Instagram itself, collecting up to one million followers. If popular people who write blogs are called bloggers, thus popular users on Instagram are known as "Instagrammers" (Latiff, 2015). According to a survey made by the Pew Research Center's Internet \& American Life Project the most frequent users of Instagram are women between 18-29 and 13 percent of all social media users do use Instagram (Brenner \& Duggan, 2013).

Farah Dhukai was born and raised in the beautiful City of Toronto, but her parents and their parents etc were born and raised in East Africa. If to go all the way back then her family originates from India. Rarah created her instagram account right after youtube channel 6 years ago. The idea of both was to self-motivation that grew into creating Farsali brand for beauty products three years after. She also opened additional youtube channel and instagram account named Farsali, in order to engage followers with brand and promote Farsali only within social media platforms, mostly within Instagram. Which helped her to use already built relationship with her followers and attract more via crowdsourcing with other beauty bloggers on Instagram.

\subsection{Word of Mouth Communication and Viral Marketing}

Keller (2013) argues that word-of-mouth marketing is an even bigger challenge nowadays because of the share ability on social media. "Consider word-of-mouth as not just "nice to have," but a game-changing element of today's marketing mix" (Keller, 2013, para. 14). According to Young (2008) there will always be consumers 
talking about companies and when they do it is more likely that people will believe them than if companies talks about themselves. The companies must have a great and consistent content to share. Content marketing is not new and because of the loss of entry barriers thanks to Internet, the content is more available than ever.

Although, eWOM was main strategy it could not deliver a sale of all products released in 24 hours, another theory was used to investigate power of digital marketing within Instagram - viral marketing. Sohn, Gardner and Weaver (2013, s.22) define viral marketing as "a marketer initiated consumer activity that spreads a marketing message unaltered across a market or segment in a limited time period mimicking an epidemic". Which is biggest part of all marketing strategy for beauty gurus that promote their own or third parties products on Instagram. To be able to get positive viral marketing, the marketing message from the company must be fast moving, convincing and self-reproducing (Sohn et al., 2013). Kotler et al. (2008) define viral marketing as the web-based conformation of word-of-mouth marketing. According to De Bruyn and Lilien (2008) the most common form of viral marketing is when the consumer taking initiative to spread information about a company or its product or service. It can occur both because people have a desire to share what they like to their friends in order to create value for them or to gain expressed incentive like financial profit.

According to Bhat and Abulaish (2013) one of the main tasks of the strategy with viral marketing is to find the right consumers with large size networks and huge impact on their social media platforms. Companies must try to communicate their marketing message with these types of consumers, with hope that they will mediate the communication with their network (Hayat \& Hershkovitz, 2018; Hayat, Hershkovitz \& Samuel-Azran, 2019).

As stated above majority of Instagram users are female, ages 18-29 that mostly interested in beauty products. Which creates more favorable platform for Instagramers, of same interest and field, to cooperate and exchange monetary rewards with each other for advertising each other's profiles. Such advertising cost may vary depending on the amount of followers of one's account and kind of ad they 
have to provide. Such an add may be as limited in time capture via "stories" or a picture on timeline, with or without promotional post.

If ten years ago scientist would study whether user has trust to technology, nowadays question changed to: "How much people trust technology and how it can influence their decision making?" Thus, to add already existing habit to shop online and high trust to online shopping could lead to the question of how this experience can be more efficient and easy for the customer but still equivalent to what is shown on picture and purchased.

To establish more about social networking sites, hashtags importance in advertising techniques next research was done and presented further.

\subsection{Prior Research}

According to Kim's research (2017) on social networking sites (SNSs) web based virtual networks can help to explore the value of social media, where instead of sharing textual information within their social network, users share images or pictorial information. Where he refers to self-monitoring traits and theirs impact on individuals' information processing. More specifically, high self-monitors are more likely to prefer image-oriented advertisements to product-oriented advertisement, whereas low selfmonitors provide more positive evaluations of product-oriented advertisements, which emphasize functional benefits over image-oriented advertisements (Snyder \& DeBono, 1985). That relates to only one part of current research and emphasizes importance of self-monitoring within digital marketing. However, it does not take into

account viral marketing, which addresses limited time frame for product oriented and image oriented advertisement. The current research suggests that users' selfmonitoring can serve as a predictor of SNS usage. The study's findings thus provide an opportunity to better understand self-monitoring effects in the SNS context (Kim, 2017).

Another research conducted by Giannoulakis (2016) based on evaluation the descriptive power of Instagram hashtags. Where Giannoulakis and Tsaapatsoulis (2016) investigated whether tags accompanying photos in the Instagram can be considered as image annotation metadata. However, images in social media, which 
constitute the great majority of Web images, cannot effectively indexed (extract relevant text description) with pure web-based techniques, mainly because the user pages in social media do not follow the classic webpage structure.

As a result, the well-known content-based image retrieval field revitalized and a more specific research area, Automatic Image Annotation (AIA) emerged (Giannoulakis, 2016). In presented above research was found that in order to achieve Automatic Image Annotation is necessary to create good training examples, i.e. pairs of images and relevant tags. Where large part of hashtags are not directly related with image's visual content. So research has to be done in order to locate and remove stophashtags and fully automated the hashtag selection procedure. As stophashtags researchers define meaningless hashtags that frequently occur in different categories and these hashtags represent noise (Giannoulakis, 2016).

By this findings could be conducted further research on hashtag relationship with images and used in developing analyzing traits of ad's posts content for clearer understanding of advertising algorithm. Which seems to be far away from current findings and requires more research being done on topic.

Another related work by Latiff (2015) focused on new business set up for branding strategies on social media focused on Instagram network. Which covers concepts of brand identity and brand image, brand community, and branding on social media. One of the most outstanding features of an Instagram resulted as the fact that it has filters that enables users' photos to stand out and appear as if it has been given a professional touch (Latiff, 2015).

The filters are so easy to operate and with just three steps, users can publish their raw photos and made it look unique and stands out according to their chosen mood. As for these business operators, although they admittedly love using the filters but when it comes to product that needs the color to be as close as the real one, very few times they will use a filter but rather to publish the photos just by enhancing the lighting and brightness (Latiff, 2015).

Next important finding derived from research described above follows. The fact that Instagram has the ability to attract a bunch of famous people to set up their own account has become an advantage to these business sellers. The sellers then will 
engage all these famous Instagrammers to help them to advertise their product with a minimal fee. According to Latiff (2015), advertising on Instagram is a huge advantage for these sellers as there's no third party involve, no fancy media or agency budget needed, so it's just between them and the owner of the account. It also gives them direct connection as once these Instagrammers post up a post that tagged their account, it will piqued the followers' interest and invited them to click on it. Once they reached the sellers' page, there are chances that they will click on "follow" if interested and this will increase their number of followers (Latiff, 2015).

Thus, it supports basis of this paper and confirms the fact of benefit in usage Instagram as advertising platform. However, given research touched eWOM strategy it did not follow further with viral marketing strategy. In his work, Latiff (2015) describes importance for the brand to be able to use eWOM as one of the most significant tools. Thus, nowadays trend of creating pre-launch panic and higher desire for consumers is not taken into account.

However, he concludes that exclusivity also plays great role in promoting the product. Exclusivity here can simply mean unique selling proposition (USP). In business, a USP is necessary to create hype for your product and set it apart from competitors. On top of that, audience needs to know what makes your product special and intrigued them to give it a try. In branding, exclusivity is another element of brand positioning whereby your uniqueness will stand out from the rest and cut the clutter of various products on Instagram (Latiff, 2015). Which emphasized important aspect of branding of product but did not connect with viral marketing.

From reviewed research derived next question on the topic. How viral marketing can be implemented within Instagram advertising for small business, specifically for Farsali brand? 


\section{How viral marketing can be implemented within Instagram advertising for small business?}

The research question is derived from previous research on topic and focused on the problem of delivering message to the customer effectively, especially before launch of product. Since, it was established that there is preference of Instagram as advertising platform due to its features. Hypothesis $\mathrm{HO}$ would be: The more small business is emphasizing exclusivity of its brand/product, the more likely it may use viral marketing.

With the constantly growing online shopping tendency more and more brands reaching out to bloggers/Instagramers, but small businesses mostly set aside because of the low profile or lack of investments. However, they successfully executing viral marketing strategy within Instagram platform without high expenses on marketing as it is. Thus, small companies get a chance to bring exclusivity and interest as for the Instagramer, as for own company.

This can be seeing in Farsali operation on Instagram, when small unknown brand paid to @HudaBeauty another very popular Instagrammer for the advertising prior product was first launched in 2014. The ad itself consisted of Huda showing the bottle with product, explaining how she is using it and that it is new, to be launched soon brand. In one month Huda advertised product three times, at the beginning of the month, middle and few days before its online launch. Two days after the launch product was sold online with the price tag of $60 \$$ for $30 \mathrm{ml}$ bottle of product with one ingredient: calophyllum inophyllum (Tamanu) oil.

Example above was presented in order to emphasize the simplicity and disproportion between what is offered/ received to the user and artificial stress brought to the advertising and promotion of it. 


\section{Methodology}

To answer research question, unobtrusive/quantitative method was used. Which included web content analysis and social media network analysis. First were investigated changes over 1 year of online marketing in social media by usage of keywords in instagram posts, that manifest name of the brand and name of the instagrammer via Buzilla tool.

Social media network analysis was approached via observing amount of followers of each instagramer, the one that advertised and the one that promoted product. With taken into account that it is particular population, leading beauty bloggers/instagramers and that it is not focused on one person but includes nodes (instagramers) with no relations.

For the representative sample, was chosen Instagram comments for analysis via Buzilla tool. And next accounts in order to capture cause effect relationship of advertising and selling the product: @farahdhukai, @hudabeauty, @farsalicare, which are great representative of small business on Instagram. Keywords used in Buzilla tool were next: farsalicare, hudabeauty, farahdhukai.

Aim of the research was to find out if there is connection between amount of followers and advertising within other more popular instagramer. And if there is any correlation within comment section and how many conversations include two or even three keywords in the same time via Buzilla tool for the past year. 


\section{Results}

Received results retrieved from Buzilla tool shown that all three keywords were used at the same time in one comment right before product was or released or stocked on the website and on the page of @farsalicare on Instagram (see appendices). Which also corresponds with observational findings such as advertising of a product on Instagram live stories by @hudabeauty in the same time frame.

Since, only qualitative results shown physical connection between usage of keywords and actual activity in comments on Instagram and announcements on the @farsalicare page of launch or restock of product, can be elaborated as positive findings. Which reflects way of using viral marketing as a stretagy for advertising small business.

However, no connection could be examined between exclusivity of the brand and its likeliness to pursue viral marketing due to lack of data. Which could occur because of privacy limitations.

From Chatter Volume analysis were received next results, where 363 discussions included @farsalicare keyword. 149 disscussions took place during past year including @farahdhukai keyword in comment and 36,890 disscussions took place mentioning @hudabeauty keyword in comments. Which is presented accordingly by $1 \%, 0 \%$ and $99 \%$ of pie chart. From the results in post section of Chatter volume 20 conversations were chosen manually due to the requirement of research. To showcase an example one of the comments presented next. "@farahdhukai FACE- $\square$ PRIMER: @farsalicare "Unicorn Essence" to Prime 口FOUNDATION: @lamer Soft Fluid... @tomford Sheer Cheek Duo "Bicoastal"

+HIGHLIGHT: @hudabeauty 3D Pink Sands “Santorini..." made on 20/07/2017 on social network Instagram. And the post on @farsalicare with a picture of a unicorn essence and comment:" Where beauty meets skincare $\$$ Meet our Unicorn Essence, Rose Gold Elixir and Volcanic Elixirt 
\#farsali \#farsalicare \#unicornessence \#rosegoldelixir \#volcanicelixir", dated 20/07/2017.

\section{Graph 1}

Chatter Volume

\begin{tabular}{|l|}
\hline @farsalicare \\
@import $\%$ Advanced $\times$ Delete Last year $\vee$ Collapse $\wedge$ \\
\hline Import $\%$ Advanced $\times$ Delete \\
@farahdhukai \\
\hline
\end{tabular}

W Import Advanced $\times$ Delete

Graph Type: Lines $\vee$ Display: Daily $\vee$ Percents and Discussions $\vee$

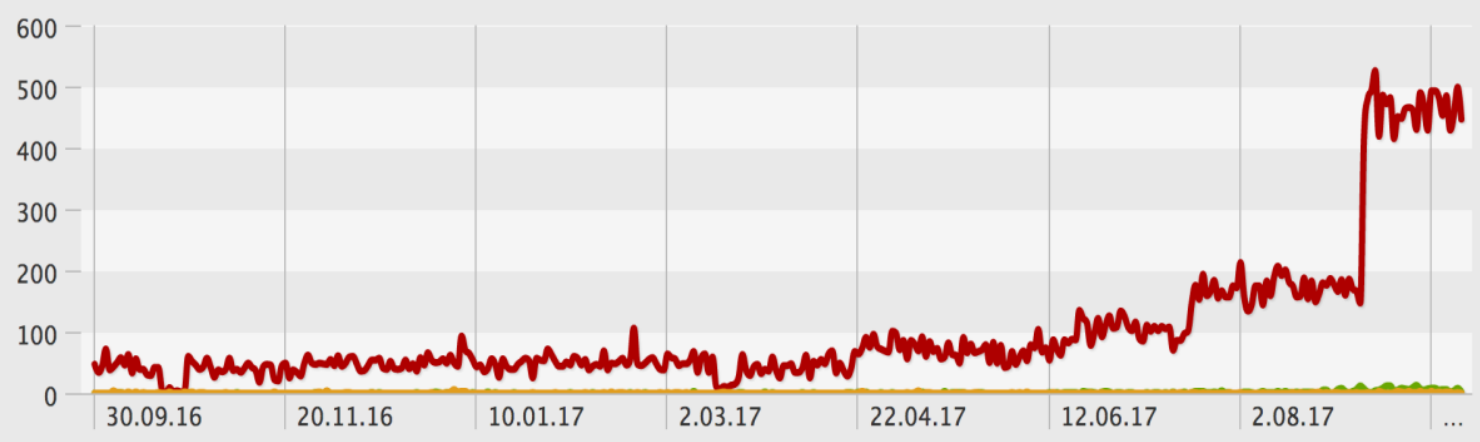

\section{Graph 2}


Graph Type: Pie

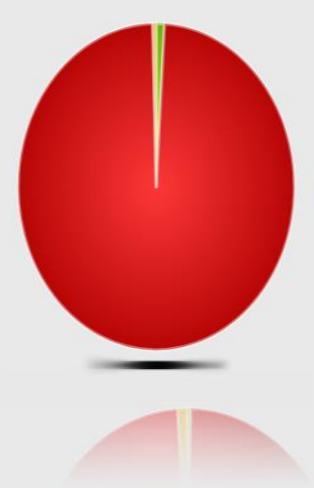

$\mid 1 \%$ \%

$199 \%$ \% Olichearaty

36,890 Discussions

$100 \%$ onsantion

149 Discussions

\title{
Excel of Chatter Volume Comment section
}

\author{
$621+80 \cdot f x$
}

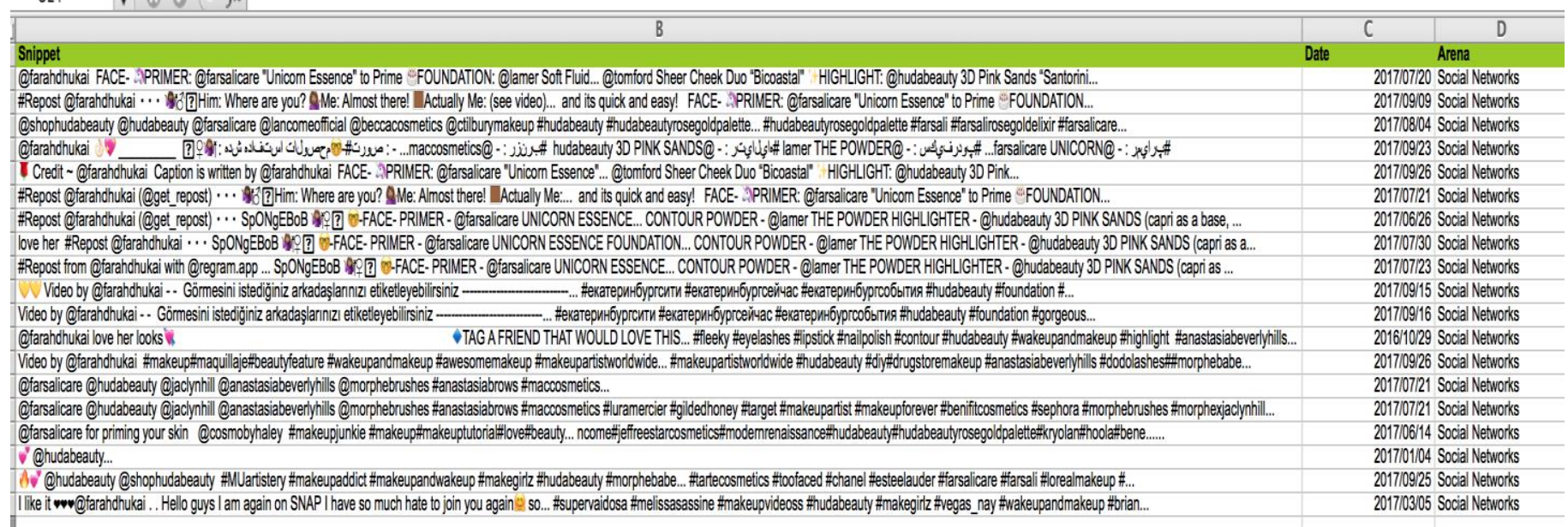




\section{Discussion}

This study created to answer the phenomenon of virtually set up businesses on Instagram as this activity has been growing rapidly where Instagram has become a popular medium to shop. Started as a Social Networking Site (SNS), Instagram has evolved in ways that users would have never imagined. When founders of Instagram kick started the project, they didn't imagine it to be a platform for businesses to grow especially home based business as their objective is based on photo sharing. From this study, the researcher has found several interesting insights to what had contributed to the growth of this phenomenon.

The power have shifted from the company to the consumers and today, companies wants to find the right consumers to associate with the company and their product and services, in case of small businesses Instagram can be easy and very comprehensive platform for such goal. Whereas, as shown in the result section, using one platform as Instagram makes it possible to present and advertise your product but not buy it straight away. Instagram is missing many features that exist in other ecommerce sites that lead to more complicated process from decision-making and finally purchasing the product. When a user wants to purchase a product he sees on the Instagram page, he will need to be transferred to at least few pages. When some of them may be main domains of the selling company or Whattsup social network 
service. Thus, on the way to final purchase there is still an opportunity to lose a client and for a consumer undone purchase.

There is another popular feature of platform that engages more and more users faster than photos, its video content. In regards to our research video content played crucial role, as it was part of live stories and become archived by the end of 24 hours from the upload moment. This segment still not opened enough to the research since there is no option to remote on live stories and more than that, there is no saved videos older than 24 hours from live stories. In order to be able to analyze and exert data from video content there should be an algorithm of encoding and associating video content and its frame, description by author.

That is the reason for such drastic growth and enlargement in successful marketing, since it is not traceable and shaped into a category or strategy by scientists.

For current work one of the main obstacles was inability to retrieve video content created by one of the Instagramers. But it shows the direction of future possible research and discovering of new connections between users and content.

Nonetheless, presented work could be taken further and the question of how Instagram can use else in terms of viral marketing analyzed via questionnaire. Such a questionnaire could consist of fifty constructive questions with already scaled answers, where 1-definatly not, 3-neutral, 5-ofcaurse. As an example, "Would you buy this product on Instagram if all you need to do is two clicks?" And adding a reverse question to have significant results, from which could be seeing tendency of consumer's behavior and grounds for new researches.

It is important to put fresh content to the account but many instagramers do not hesitate to use previously used content and repeat themselves, which leads to noise in analysis can bring biases into research.

That said there are a variety of angles to look from while examining social network connection to ecommerce and each of them can assist in future developments. In order to perform them much more research should be focused on the quantitative side. To be capable of analyzing data and to have more access to it within social networks sites researchers should gain more instruments that can help in this 
process.

\section{Conclusion}

Interactive Social media bring a lot of opportunities for small businesses, starting from saving on spending for physical shop and at the end, coordinating your business from any location in the urban world. Also, with fast growing technologies there is a need of adaptation as for technology as for user demand. Which tights both in interaction and requires mutual work. The faster ecommerce transfers to Instagram the more there is a need for acknowledgment, not only for businesses and marketers but also for users. Because, no launch will be successful unless proper campaign is done by sellers and users guided through new or innovational features offered to them. 


\section{Reference List}

Bhat, S.Y. \& Abulaish, M. (2013). Overlapping Social Network Communities and Viral Marketing. Computational and Business Intelligence (ISCBI), 2013 International Symposium on (pp. 243-246). IEEE.

Brenner, J. \& Duggan, M. (2013). The Demographics of Social Media Users - 2012. Pew Research Center's Internet \& American Life Project. Retrieved 30 September 2017 from http://www. pewinternet.org/2013/02/14/the-demographics-of-social-mediausers-2012/

De Bruyn, A. \& L. Lilien, G. (2008). A multi-stage model of word-of-mouth influence through viral marketing, International Journal of Research in Marketing, Volume 25, Issue 3, September 2008, Pages 151-163, ISSN 0167-8116,

Hayat, T., Hershkovitz, A., \& Samuel-Azran, T. (2019). The independent reinforcement effect: The role diverse social ties play in the credibility assessment process. Public Understanding of Science, 28(2), 201-217.

Hayat, T., \& Hershkovitz, A. (2018). The role social cues play in mediating the effect of eWOM over purchasing intentions. Journal of Customer Behavior. 17 (3), 173-187.

Keller, E. (2013). Word-of-Mouth Goes Mainstream, Is Now Measureable. Three Useful Insights for Marketing's Not-So-Silent Partner. Retrieved 30 September 2017 from http://adage.com/article/guest-columnists/word-mouth-mainstream$\underline{\text { measureable/239501/ }}$ 
Kotler, P., Armstrong, G., Wong, V. \& Saunders, J. (2008). Principles of marketing: European edition. (5. ed.) Harlow: Financial Times Prentice Hall.

Snyder, M., \& DeBono, K. G. (1985). Appeals to image and claims about quality: Understanding the psychology of advertising. Journal of Personality and Social Psychology, 49(3), 586.

Sohn, K., Gardner, J. T. \& Weaver, J. L. (2013). Viral marketing - more than a buzzword. The Journal of Applied Business and Economics, 14(1), 21-42.

Young, B. (2008). Word-of-mouth: Marketing that works. Franchising World, 40(12), 64-65.

\section{Appendies}

\section{Instagram dictionary}

Snap: Taking a picture.

Tag: Add a person or a geographic place by make their names clickable.

Hash tag (\#): A function that makes the words you write after using \# (a hash tag), when writing about your posts, searchable. When using hashtags you tag the most important words and make them clickable, which makes it easier for users to find posts with themes that interest them.

Followers: The users that are interested in an account and want it to appear on their newsfeed can choose to follow it and will be followers of that specific account.

News feed: A feed where you can see the post from the users you chose to follow.

Filter: A function that makes it possible to put different filters on the post you share on Instagram.

Like: A function that makes it possible to "like" what others have posted on Instagram, the amount of likes will be shown below the post.

Popular page: A page where the most liked posts by the most active and liked accounts are visible to other users. 


\section{Visual presentation of brand Farsali on Instagram}
(0) Instagram
Q Search

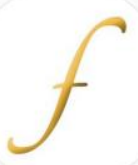

\section{farsalicare Follow}

\section{3,363 posts $\quad 1.2 \mathrm{~m}$ followers $\quad 17$ following}

FARSÁLI - Beauty with Benefits The 1st makeup-enhancing skincare brand where makeup and skincare meet and fall in love www.farsali.com
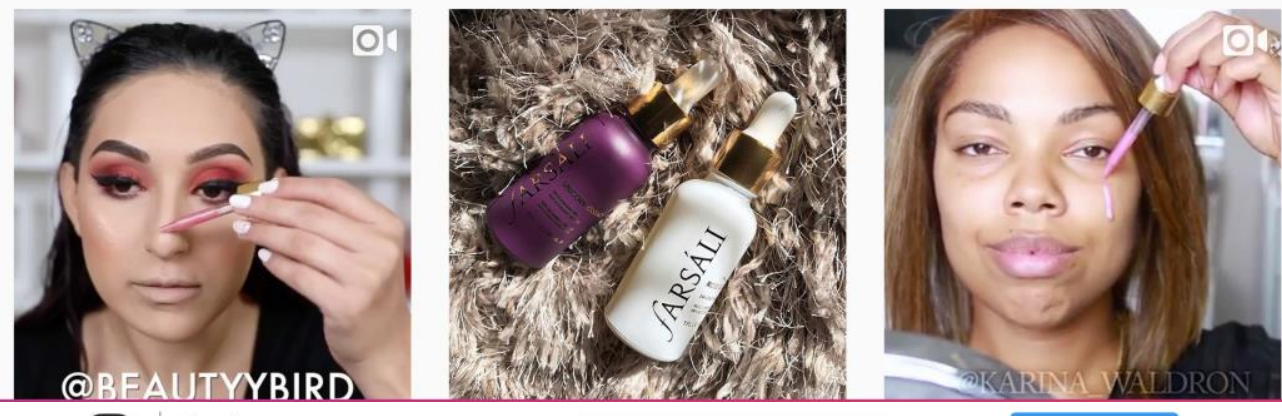

(0) Instagram

a Search

Get the app

Sign up | Log in

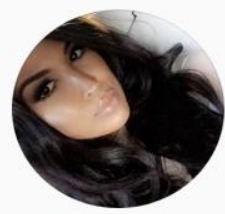

farahdhukai Follow

726 posts

$5.7 \mathrm{~m}$ followers

795 following

Farah D $\mathbb{\perp}$ Beauty•DIY ingmt.farah@gmail.com it: Snapchat: farahdhukai YouTube: farahdhukai Check out my YouTube channel 4 tiny.cc/c2qvfy
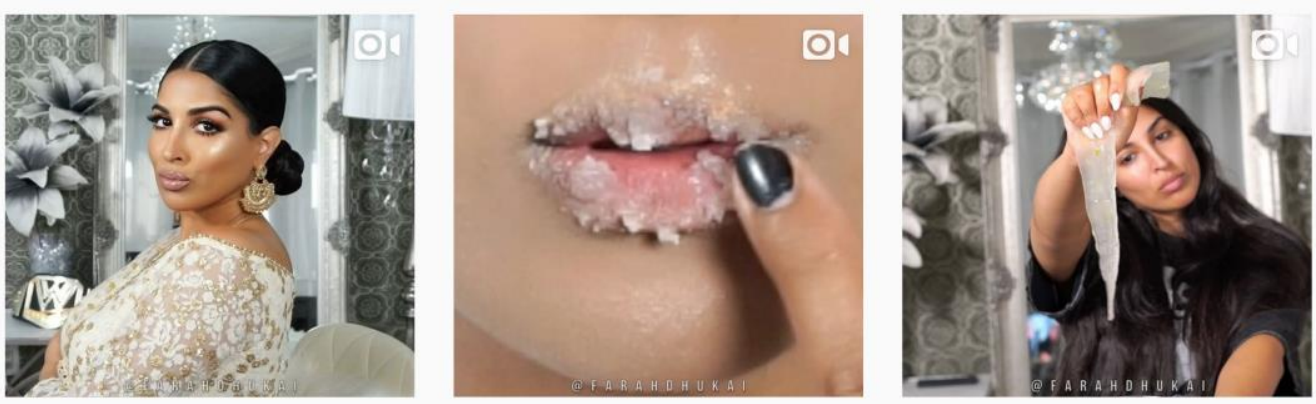
(0) Instagram
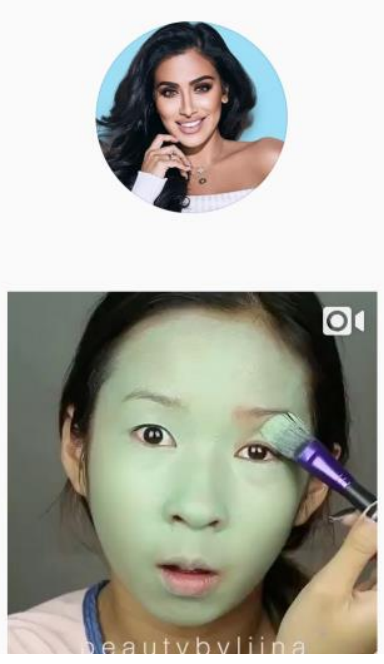

\section{hudabeauty Follow \\ 12,008 posts $\quad 21.6 \mathrm{~m}$ followers $\quad 265$ following}

Huda Kattan MUA \& Blogger Turned Business Woman Top Beauty Influencer on Instagram LOVE to support artists Turn on Notifications is SNAPCHAT REALHUDABEAUTY hudabeauty.com
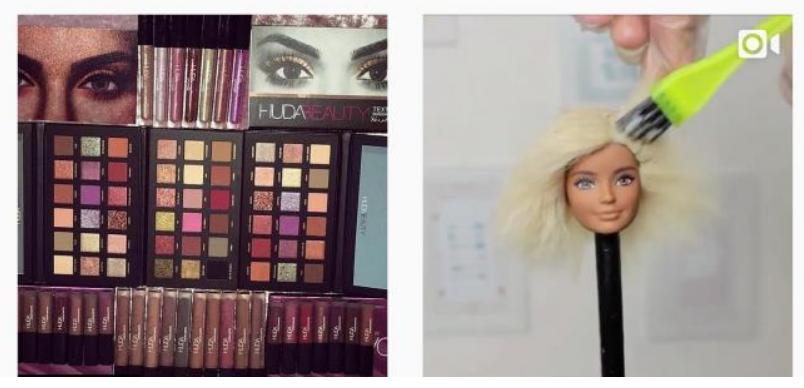